\title{
Social Responsibility and Environmental Sustainability: The Case of Caixa Geral de Depósitos (Portugal) and Vale (Brazil)
}

\author{
José António Candeias Bonito Filipe \\ Instituto Universitário de Lisboa (ISCTE-IUL), UNIDE-IUL, Lisboa, Portugal \\ Manuel Francisco Pacheco Coelho \\ Instituto Superior de Economia e Gestão (ISEG-UTL), SOCIUS, Lisboa, Portugal \\ Manuel Alberto M. Ferreira \\ Instituto Universitário de Lisboa (ISCTE-IUL), UNIDE-IUL, Lisboa, Portugal \\ Ivo Cunha Figueredo \\ Instituto Universitário de Lisboa (ISCTE-IUL), Lisboa, Portugal
}

\begin{abstract}
Social responsibility requires a set of duties and obligations, whether individuals or firms in relation to society and to the communities in which the organization is operating. The tradition of social intervention in Portugal dates from the fifteenth century and the founding of Mercy. However, environmental issues have never been felt in a sensitive position in responsible business, given the weakness of industrial development which lasted until the 60's. In Brazil, the corporate social responsibility is still particularly a big challenge, since the actions of social responsibility have not contributed effectively to improve the living conditions of society and the transformation of existing social reality. The purpose of this study is to emphasize the perspective of environmental sustainability that underpins the more general concept of social responsibility and, through the case study Caixa Geral de Depósitos, assess the strengths and weaknesses of the development of measures of social responsibility in this area in Portugal, and present the case of the company Vale, carrying out business in Brazil.
\end{abstract}

Keywords: social responsibility, sustainable development, environmental sustainability, Caixa Geral de Depósitos, Vale

\section{Introduction}

An organization must be socially responsible. For that, the organization has to take into account all stages of decision-making process and has to shape it in the context of the community in which it appears. The organization must be active and lead the economic, technological and human development. To that extent, its performance requires full respect for human rights, investment in personal enhancement, environmental protection, combating corruption, compliance with social norms and respect for ethical values and principles of

José António Candeias Bonito Filipe, assistant professor, Instituto Universitário de Lisboa (ISCTE-IUL), UNIDE-IUL.

Manuel Francisco Pacheco Coelho, assistant professor, Instituto Superior de Economia e Gestão (ISEG/UTL).

Manuel Alberto M. Ferreira, full professor, Instituto Universitário de Lisboa (ISCTE-IUL), UNIDE-IUL.

Ivo Cunha Figueredo, graduate student, Instituto Universitário de Lisboa (ISCTE-IUL). 
the society in which it operates. Social responsibility requires a set of duties and obligations to be accomplished by individuals and firms in relation to the society and to the communities.

In Portugal, the tradition of social intervention dates from the fifteenth century and the founding of Mercy. However, environmental issues have never been felt in a sensitive position in responsible business, given the paucity of industrial development which lasted up to 60's.

Although traditionally, social responsibility has come to be practiced by larger firms in an informal manner in Portugal, the emergence of "social responsibility" as a theme of autonomous management brought a new perspective on the part of some agents which led some firms with greater economic dynamism to become interested in environmental issues, beyond the more traditional paternalistic sense which put the accent on the relationship with employees.

In Brazil, the basic needs of large segments of the population are still not being met. Issues related to survival, hunger, unemployment and social exclusion, among others, lead discussions about social responsibility of business to a lower level. In this sense, it is necessary an important debate on the corporate social action in Brazil.

The discussions about corporate social responsibility in the United States and Europe dealt with problems relating to environment and consumer rights. The Brazilian reality raises other questions, much more urgent to be tackled and solved. The concept of social action is the one that, currently, more closely reflects the performance model of the Brazilian companies that practice social responsibility, as defined by the IPEA. In that definition, CSR complies the actions that are not obligatory, performed by the companies through donations or projects in areas such as social assistance and food, among others. Some interesting developments in this area are made by some companies in Brazil.

The examples of Caixa Geral de Depósitos (CGD) in Portugal and Vale in Brazil are presented to show important strategic policies in companies dealing with social responsibility.

The purpose of this study is to emphasize the perspective of environmental sustainability that is comprised in the more general concept of social responsibility. Through the case study of Caixa Geral de Depósitos, it is intended to analyze the strengths and weaknesses of the development of measures of social responsibility in this area in Portugal. At the same time, Vale case is studied to establish comparative analysis between two cases in two different locations and two economic spaces with particular economic development contexts. Vale is seen in this particular study analysing what the company is doing now on this matter in Brazil.

\section{The Concept of Social Responsibility}

According to European Commission Green Paper (2001) conceptualization associated with the idea of social responsibility concerns the situation according to which companies decide on a voluntary basis and contribute to a fairer society and a cleaner environment.

Corporate social responsibility refers to the adoption of a model of business management in which the companies, being aware of their social commitment of co-responsibility in social and human development preserve and respect the interests of different parties, their stakeholders, incorporating different needs of the business planning and operating them through their decisions and activities.

Although much discussed, the concept is not yet finally stabilized. In any case, the effort of researchers to 
differentiate the simple idea of charity has proved essential to its proper scope and understanding by companies and managers.

There are countless interpretations and definitions of corporate social responsibility.

Possibly the best way to analyze the concept of corporate social responsibility is to identify some different views (Melo Neto \& Froes, 2001):

- The social responsibility as an attitude, an ethical and responsible corporate behaviour: Concept and duty associated with the organization's commitment to assume a transparent, accountable posture, and ethical relationships with its stakeholders (customers, suppliers, government, community in general);

- The social responsibility as a set of values: not only incorporates ethical concepts, but a series of other concepts that give sustainability, for example, self-esteem of employees, social development and others;

- The social responsibility as corporate strategic posture: The quest for social responsibility is seen as a social action strategy that generates positive return to business;

- The social responsibility as a relationship strategy: Focusing on quality improvement of relationships with different stakeholders, i.e., social responsibility is used as a strategy of marketing relation, particularly with customers, suppliers and other collaborators;

- The social responsibility as institutional marketing strategy: The focus is on improving the corporate image. It is the institutional gains that justify the investment in social projects undertaken by the company.

- The social responsibility as a strategy for recovery of the shares: The reputation of a company and the value of its shares on the market go together.

- The social responsibility as a human resources strategy: The actions are focused on employees and their families with the aim of increasing personnel satisfaction and generating increased productivity;

- The social responsibility as a strategy for recovery of products/services: Beyond the mere affirmation of quality of the products and services of the company, is the purpose of guaranteeing them the status of "socially correct";

- The social responsibility as a strategy of integration in the community: The firm seeks to improve its relations with the community and redefine innovative ways to keep it inserted;

- The social responsibility as a strategy of social development in the community: The organization takes over the role of agent of local development, along with other community organizations and the government itself;

- The social responsibility while promoting individual and collective citizenship: By their actions, the companies help their employees to become true citizens and contribute to the promotion of citizenship in the community;

- The social responsibility as an exercise in ecological consciousness: The social responsibility is seen as leading to environmental liability company to invest in education and preserving the environment by becoming a broadcaster of values, attitudes and environmental practices;

- The social responsibility as a strategy for social inclusion.

All these dimensions are, in fact, a part of a comprehensive overview of the concept. Thus, we can withdraw this central idea, as greatest common divisor: Corporate social responsibility as a voluntary integration of social and environmental concerns in the daily operations of the organizations and interaction with all stakeholders.

Social responsibility requires the accomplishment of a set of duties and obligations, whether individuals or 
firms in relation to society and the communities in which the organization operate.

Social responsibility presupposes the existence of an ethical and responsible corporate behaviour; a set of values; an entrepreneurial strategic posture; a relationship strategy; a strategy of institutional marketing; a strategic valuation of the shares; a human resources strategy; a strategy to develop products/services; a strategy of integration into the community; a strategy of social development in the community; the promotion of individual and collective citizenship; the exercise in ecological awareness and professional training. Those are the multiple aspects that constitute an integrated support to a responsibility that organizations must take, including to ensure their long-term operation.

\section{Environmental Accounting}

The social accounting arises in order to contribute effectively to the prosperity of organizations and nations, transforming the accounting information system in a broader package, whereby statements are presented not only financial and economic, but also those of character social and environmental indispensable for the analysis, control, evaluation and decision-making, and of the entities in the world context of globalization and constant change (Kroetz, 1999).

Environmental accounting can be defined as the record of environmental assets: assets, rights and environmental obligations, a certain entity, and their mutations, expressed monetarily.

Paiva (2003) defines it as the activity of identifying data and records of environmental events, processing and generating information that assists the user serving as a parameter in their decision-making.

For Ferreira (2003), the development of environmental accounting results from the need to provide information tailored to the needs of environmental management. The author states that the environmental accounting does not refer to a new accounting, but a set of information to report fairly, in economic terms, the actions of an entity that alters its assets. This set of information is no other accounts but a specialization. This is a new base and a new system of recognition and measurement of costs, including externalities.

For Bergamini Jr. (1999), environmental accounting aims at the registration of the company's transactions that impact on the environment and their effects that affect or should affect the economic and financial position of the business, ensuring that costs, environmental assets and liabilities are accounted for in accordance with generally accepted accounting principles or in his absence, with the generally accepted accounting practices and environmental performance and with the wide transparency that users of accounting information need.

For the Environmental Reporting Guidelines cited by Tinoco and Kraemer (2004), environmental accounting is a framework that quantitatively estimates the environmental conservation efforts in monetary terms. It is also a significant technique that may indicate the state of environmental conservation to stakeholders. This accounting is more ambitious than the traditional, since it aims to know the negative externalities and record, measure, assess and disclose all environmental events.

Yet, environmental accounting can provide regular information to internal and external users about the environmental events that caused changes in the assets of the respective entity, measured in currency.

\section{Environmental Event}

Environmental event is any entity's interaction with the environment that generates economic consequences of present or future, in view of the regulatory standards or social responsibility that is subject to a 
specific company.

Examples of environmental events have been spending on development or acquisition of technologies, machinery and equipment antipollution; search for waste reduction, employee training methods of clean production and the laws, raising revenue as a consequence of materials recovery (recycling), among many others.

Tinoco and Kraemer (2004) list events and environmental impacts related to operational activities of various sectors that affect the assets and business continuity, quality of life, fauna, flora, rivers and seas, and that therefore shall be subject to registration, collection, measurement, evaluation and dissemination by the accounts, highlighting in particular:

- Coal mining: Causes impacts on the environment evidenced in the atmosphere, soil and surface water and groundwater;

- Steel: Degradation of water quality, which requires local water-dealing, construction of landfills, air pollution, pollution emissions from power plants, especially particulate matter, release of oils and greases, organic loading, soluble manganese, ammonia, etc. involving investments to control them;

- Other activities that also deserve mention: The production of lime, cane sugar, pulp and paper production and the oil industry.

It is based on these events that it is possible to quantify and record, through the accounting techniques, the environmental interactions surrounding businesses and entities.

\section{Advantages of Environmental Accounting}

According to Tinoco and Kraemer (2004), several advantages related to the use of accounting in the environmental focus may be pointed, such as:

- Measurement and allocation environmental costs, allowing a continuum of planning applications;

- Measurement of environmental liabilities;

- Intensive use of explanatory notes and environmental performance indicators;

- Being able to accurately verify the reductions in resources such as water, energy, soil and other potential physical environment;

- Making decisions based on the costs and benefits recorded in their own environmental accounting;

- Providing information and statements about the effectiveness and economic feasibility of the environmental actions;

- Publishing the social and environmental issues, creating transparency and social interest;

- Constant corrections of environmental actions, reducing the level of aggression against nature in the manufacture of products and services essential to the population;

- Quality data analysis and interpretation by both internal and external audiences, allowing an evaluation of the quality of environmental management of the entity.

\section{Social Responsibility and Environmental Sustainability in Portugal and Brazil}

\section{Environmental Sustainability}

The concept of sustainable development has emerged from studies of the United Nations on climate change in the early 1970s, as a response to the concern of humankind, given the environmental and social crisis that has befallen the world since the second half century. This concept, which seeks to reconcile the need for 
economic development of society to promote social development and respect for the environment, today is a vital topic on the agenda for discussion on a variety of organizations, and with different levels of organization society, as in discussions on the development of cities and regions, current day-to-day society. This text presents the evolution of the concept since its inception to the present.

The year 1968 was the first serious sign of popular discontent with the model of industrial capitalism towards the end of its cycle, with the outbreak of student protest in the chain, started in Paris in May 1968, rising Berkeley, Berlin and Rio de Janeiro.

Breaking the walls of the citadel economic, environmentalism is to question the economic rationality in terms of their own criteria. More specifically, the new debate shows that, compared to several problems and dilemmas that industrial development poses, the solution may not require a new jolt, but the adoption of restrictive measures to increase economic production, which raises the idea of ecological rationality as the basic principle and limits the economic rationality and self development.

The Club of Rome, an entity formed by intellectuals and businessmen, who were not environmentalists, was an initiative that grew out of discussions regarding the preservation of natural resources of planet earth. He produced the first scientific studies about environmental preservation, which were presented between 1972 and 1974, and that related to four major issues that should be resolved in order to reach sustainability: control of population growth, control of industrial growth, lack of production food, and depletion of natural resources.

Development and environment have merged on the concept of eco-development, which in the early 80's was supplanted by the concept of sustainable development that has been adopted as the official expression in UN documents, IUCN and WWF.

\section{Environmental Sustainability as a Pillar of Corporate Social Responsibility}

The concept of social responsibility can be understood at two levels:

- The internal level, it relates to workers and, more generally, with all actors and stakeholders (who are affected by business and, in turn, may influence the results);

- And the external level which considers the consequences of the actions of an organization on its external environment, including, among other things, its business partners and the environment.

Before proceeding, let's prior to submit an evaluation of the more general features of social responsibility in Portugal to better enter the CGD event in the general context and highlight its special features. Later some features of social responsibility in Brazil will be presented as well.

CSR in Portugal. The tradition of social intervention in Portugal, dates from the fifteenth century and the founding of Mercies.

Environmental issues have never been felt in a sensitive position in responsible business given the paucity of industrial development that lasted up to 60 's. Although, traditionally, social responsibility have come to be practiced by larger companies, in an informal manner, the emergence of "social responsibility" as an independent theme/subject in management (following the Lisbon Summit in 2000), caused a new perspective to some agents. The demand from large companies to distinguish themselves in this process with the ultimate goal to ensure/enhance the "brand image", has led some larger enterprises with greater economic dynamism to become interested in environmental issues, beyond a more traditional and paternalistic position which put the 
accent on relationships with employees.

Some studies ${ }^{1}$ carried out previously have sought to characterize the state of the art of social responsibility in Portugal and uncover the motivations that lead Portuguese companies to become interested in this type of action. Simultaneously wonder about the difficulties and bottlenecks that hinder the development of more effective action to corporate social responsibility. Next, some of the most relevant conclusions of this analysis are presented:

Firstly, it is important to highlight the fact that it is not yet well known the concept of social responsibility and it is especially lower (compared to European levels) the percentage of consumers self-considered as "activists of social responsibility".

However, after the "boot" definitive, located somewhere in 2003/2004, with the emergence of new organizations related to social responsibility, the significant increase of reports of social responsibility and the media attention around the issue, the current scenario is a gradual increase of companies active in social responsibility and in the monitoring and dissemination of its outcome. This is translating into the adoption of codes of conduct in relation to the employees, customers and community, adoption of certifications within the product quality and service as well as environmental quality, improvement of hygiene and safety in workplaces, etc..

Secondly, the main motivations that lead companies to be socially active are emphasized. The results of investigations carried out do not always seem particularly consistent. According to some of these surveys, the companies' main reasons for their own social responsibility are related to ethics and to the improving of community relations. These aspects seem to be thus in a much better position than that resulting from the trade benefits that may result from a position of "sympathy" for the community. It seems to be inferred that what makes companies take the social responsibility is more the domain of "should be", than the understanding of the benefits that may accrue to the business itself.

In terms of environmental responsibility motivations arise primarily from the need for regulatory compliance, cost reduction and improved image with customers. The activity of social responsibility is also seen as a way to remedy the increasingly intense pressure from the community on issues that relate to the use of natural resources and preserving the ecological balance of the planet.

In any event, when asked about the benefits associated with social responsibility results appear more clarified:

- Improving the brand image of the company, ensuring customer loyalty and other employees;

- The best internal conditions of operation, with workers identified with the objectives of the company, with high self-esteem and "team spirit”, ensuring high productivity;

- Improving the relationship with the community and the public, ensuring a comfortable position, safe, with "confidence in the future" or in how the community recognizes the company wants for possible support from governments at different levels.

\footnotetext{
${ }^{1}$ CECOA (2004), Responsabilidade Social das Empresas_Estado da Arte em Portugal, 2004, Centro de Formação Profissional para o Comércio e Afins, Lisboa.

DELOITTE (2003), O Desafio do Desenvolvimento Sustentável nas Empresas Portuguesas, Management Solutions, Relatório, Deloitte, Lisboa.

KPMG (2007), Estudo da KPMG sobre a Publicação de Relatórios de Sustentabilidade em Portugal, KPMG Advisory, Consultores de Gestão; BCSD Portugal; Informa, D\&B.
} 
Here, the activity of social responsibility is sustained on a more adjusted level, not to be confused with mere charity and reset the social responsibility in the centre of business performance perspective.

In Portugal, the social responsibility is still essentially of internal sense. To some extent, it still favours the more patronizing aspects of industrial relations (with the support of health, culture and sport of employees and family members) but the progressive entry into other areas (such as the environment) seems unstoppable as companies increasingly realize that altruism and ethics underpinning social responsibility, "also yields".

Finally, the main barriers that were identified in the involvement of companies with social responsibility concern:

- The lack of information on this subject (especially for smaller firms and more traditional management);

- Lack of time, human resources, knowledge and money to develop these activities and their assessment through the reports of social responsibility;

- The lack of interaction between various functional departments and decision-making levels within the company;

- And their own inability to identify the links between it and the business corporate social responsibility.

With regard to environmental responsibility as main obstacles appear to result from the lack of human and financial resources, attitude and business culture and the lack of information associated with environmental issues. Say it is basically a matter involving the financial capital, but eventually has more on its core areas of human and social capital.

CSR in Brazil. The case of Caixa Geral de Depósitos is particularly interesting and an example from which to draw some significant indications of good practices to develop this area and so is the example of Vale in Brazil.

In Brazil, studies about CSR are still in a preliminary phase, but motivations seem to be similar. The interventions are perhaps different because concerns and objectives are specific.

Although with regional differences in the way of realization of social action for communities, donating resources is the most frequently used by many companies from all regions, and in South and Southeast, this donation is directed to organizations running social projects.

In the northeastern region of Brazil, the large majority of donations of funds are held by companies for direct assistance to needy individuals and communities. However, from the real meaning of corporate social responsibility, donating resources is not the essence, but the severity of problems in Brazil and the large proportion of the population lives below the poverty line make the social performance a big problem.

Nowadays, there are already many actions being planned by companies in order to incorporate activities of environmental sustainability and contribute through programs to the welfare of populations and resources preservation.

\section{CGD and Environmental Sustainability}

The case of CGD is particularly interesting to assess how environmental issues have come to integrate the 
concerns of social responsibility in Portugal ${ }^{2}$.

\section{Mission and Goals}

In 2009, CGD joined the United Nations Environmental Programme for the Financial Sector (UNEP-FI) and became the first Portuguese bank to join this program.

Since 1991, when it was created, UNEP-FI works the themes of sustainability in the financial sector with the aim of promoting good practices in the international financial institutions. This program reflects the recognition by the United Nations concerning the role of this sector in promoting sustainable development in that the processes of financial intermediation have repercussions in investment programs and, indirectly, in the allocation of natural resources.

Sustainable development is aimed at rational utilization of natural resources while maintaining capacity for renewal and ecological stability and respect for inter-generational solidarity. According to the Brundtland Report (1987), sustainable development is one that meets present needs without compromising the ability of future generations to meet their needs.

The accent on the issue of environmental sustainability and eliminating poverty is key aspects of this new vision, which is raising the banner of growth with quality of life based on three pillars: economy, society and environment, combined with the issues of governance.

This adherence to the program highlights CGD concerns with the long term and confirmed its activity in supporting environmental sustainability. The basis is the conviction that the principles of sustainable development will form the basis of guidelines for future development. According to Mr. Faria de Oliveira, President of CGD, the times where structural changes are the ethical, environmental and social have been gaining weight. There are conditions to innovate and develop a better society and that membership of the UNEP-FI is a public commitment to sustainable development.

This commitment of CGD with environmental sustainability and corporate social responsibility in general seems to be, according to the statements of those responsible, the "genetic code" of the company/group.

Built in 1880, the Caixa Económica Portuguesa, as then called, revealed at once their social concerns being intended to receive the savings of the less wealthy and providing a "nest egg" in the long term. By 1885, with the reform, Caixa Nacional de Aposentações (National Fund for Retirement) was born. After, CGD was going to be established as Caixa Geral de Depósitos e Instituições de Previdência. In the Estado Novo regime, CGD became a key institution in the operations of agricultural credit and industrial, and in 1969 assumed a central role in housing loans. All these aspects permit to understand the role that public authorities were successively assigning to the Caixa Group, the largest institution of public nature on the financial sector.

As you can read in a text of the Office of Historical Heritage (Gabinete do Património Histórico) of CGD — “From the History of the institution over 133 years, CGD served various aspects of Portuguese society, having had in mind the moral principle of social intervention".

The great values that guide the work of CGD and are the basis of its performance in terms of social responsibility are appreciable in the Code of Conduct issued by the institution and designated in the Good Government Report.

\footnotetext{
${ }^{2}$ CGD, Relatório Sobre o Governo da Sociedade, 2008; CGD, Relatório de Responsabilidade Social; CGD , www.cgd.pt.
} 
The commitment of CGD is immediately identifiable, if we hold fast to its mission.

According to published texts, CGD's mission is consolidating its position as a group structuring the Portuguese financial system, distinguished by strong accountability and relevance of its contribution to economic development and to strengthen the competitiveness, innovation and internationalization of Portuguese companies.

In this context, the group's strategic priorities defined for the three years 2008-2010 included the supporting of the cultural and social development, promoting sustainability and being a reference to the Good Government in Portugal.

These guidelines are then translated into 19 management priorities that include, among others:

- To boost the performance at the cultural level, and promote social sustainability;

- Proactive in developing best practice governance and ethical conduct.

CGD has adopted the principles of good governance and public sector undertakings (Council of Ministers Resolution 49/2007) and undertook initiatives for compliance including preparation of an annual business plan.

\section{Caixa 2010, Zero Carbon Strategy}

By the end of the twentieth century, humanity faces the challenge of climate change and overuse of natural resources, and issues that dominate the UN agenda. This has promoted a fundamental discussion about a new development model.

The scientific evidence of the phenomenon of climate change suggests a range of impacts that are not only environmental but also economic and social. The impacts are being felt in politics, markets and quality of life, affecting employees and customers of CGD, worldwide.

It is clear that this new reality changes the logic of economic decision imposing new requirements for investment and risk management, while encouraging new markets (such as renewable energy) and adding new financial solutions. CGD sees this and recognizes this as an opportunity.

In this line, promoted by CGD since 2007, the program Caixa Zero Carbon is a strategic program that aims to help reduce the environmental impact of its activities while it induces good practices among its employees, customers and society in general.

These are ambitious objectives involving:

- More knowledge about the carbon footprint/emission levels of the activities of Caixa to allow the setting of reduction goals;

- More economic and energy efficiency, including through the adoption of measures to gain the use of renewable energy;

- Monitoring and evaluation of performance at this level;

- And new business development to strengthen the group's position in the domestic market - with new solutions to support and incentives to customers of cash to change their energy bill, support for demonstration projects in the fields of energy efficiency and promoting education and literacy carbon to employees and customers.

The Caixa Zero Carbon Program 2010 implements the strategy acting on five axes:

(1) Information-Case reports on carbon reductions; 
(2) Internal Action-Caixa reduces energy consumption and carbon emissions;

(3) Compensation-Caixa offsets carbon emissions inevitable;

(4) Market-Caixa promotes low carbon business;

(5) Communication-Communicate through Caixa Carbon Zero.

\section{The Projects}

Central solar térmica (thermal solar central). One of the most visible projects to the reduction of $\mathrm{CO}_{2}$ emissions was the installation of solar panels on the roof of the headquarters building of CGD, transforming this building, located in Lisbon, in a huge Central Solar Thermal.

The installation of 150 of solar collectors on the roof $\left(1,600 \mathrm{~m}^{2}\right)$ of the headquarters building at Avenida Joao XXI, allows the production of energy used to heat water for air conditioning systems and plumbing. In total, there is a saving of more than 1 million kWh of electricity per year (about $5 \%$ of global consumption).

The plant has a system for monitoring the energy produced, allowing analyzing the performance of the facility, and outlining a possible expansion of the use of solar energy to other buildings in CGD.

The Thermal Solar Central CGD, along with other energy efficiency measures already implemented, results in electricity savings equivalent to annual consumption of about 2,000 people, thus preventing the annual emission of more than 1,700 tonnes of $\mathrm{CO}_{2}$.

This office building has a certificate of Energy and the Ambient Air Quality, issued by ADENE-Energy Agency, with the highest $\mathrm{A}+$ rating.

The policy of energy saving is extensible to the network of agencies that is being gradually equipped with PV.

Dia a dia carbono zero (day to day zero carbon). Along with new technology and with the direct participation of employees, Caixa has been producing a kind of guide on best environmental practices to adopt in our daily lives, whether at work or at home, which is available (PDF) in the site of Caixa.

The mission of awareness extends to the general public through the production of the TV show "O Planeta Agradece" (The Planet Appreciates), an item on the radio and a "blogue". This program is part of the Caixa Zero Carbon Program 2010, and aims to promote behaviours that help Caixa to reduce her own emissions. Simultaneously, it is to be replicated in a larger universe, to help the country meet its international commitments in this matter. Day by day, zero carbon is a program involving customers and employees around the world in combating climate change.

Floresta caixa (caixa forest). Of vital importance to the planet as $\mathrm{CO}_{2}$ sinks, the forests have, also, been addressed in the program. The forests are a major renewable resource of Europe and the most important component of nature within EU. In Portugal forest (occupying nearly $40 \%$ of the country) constitutes an important area of activity that involves more than 150 thousand workers. Forests are also essential in promoting biodiversity, protection against soil erosion, correction of water regimes and air quality. It is therefore essential to promote effective forest management as a way to preserve and foster an important renewable resource, while contributing to meeting the emission limits set for Portugal under the Kyoto Protocol.

The program Floresta Caixa represents a set of initiatives aimed to contribute to the construction of a new forest in Portugal. These are developed in partnership with some major environmental groups and linked to the stakeholders in the sector such as QUERCUS and ANEFA (National Association of Business-Agriculture, Forestry and the Environment). 
The actions that the program will materialize: recovery of areas burned and the creation of sustainable forests with preservation of native species. It includes several projects for forestation and raising awareness of the importance of the forest.

Environmental awareness. In the field of the Forest Environmental Awareness-Caixa includes initiatives aimed to promote the adoption of appropriate environmental behaviour. In addition to the above set of actions, we can cite the sponsorship of the Conference of Al Gore in our country and Portugal's edition of the book An Inconvenient Truth.

In the "lounge" area of the headquarters of Caixa there are several brochures available on forests and on the theme of climate change. Shares of Christmas "for a better future" call attention in this court, to the importance of forest preservation... and for indigenous species to be preserved.

It also counts the support measures to forestation with children and young people from schools, participation of employees and their families.

Cartão caixa carbono zero (caixa card zero carbon). One of the recent innovations in this field gives the name of Caixa Card Zero Carbon (the card that embedded in nature, according to advertising copy CGD) and represents another step in implementing the strategy of CGD in combating climate change. It is a card truly innovative, unique of its kind in Portugal.

Integrated in the program Caixa Zero Carbon 2010 (market axis), this Caixa Card Zero Carbon intended to be a means of encouraging a lifestyle of low carbon and allows its user to offset emissions that can' not avoid.

The card provides special conditions in the purchase of goods and services with greater energy efficiency and better environmental performance, providing a solution that simultaneously reduces emissions, preserving the planet, and provides a significant financial savings for its user. Presents a set of features that make it attractive for the user, in particular, on favourable terms involving the return of annuities according to their original use and the amounts reached in the transactions, the flexibility of the conditions and terms of payment and in consideration of an interest rate of operations truly competitive.

Caixa Card Zero Carbon is a genuine product of low carbon, in which key elements were designed to minimize the effects of climate change. Firstly, because it is a credit card made from recycled material, free of chlorine and that fosters communication by electronic means, thus thought to cause minimal effects on climate. By contributing to projects that absorb or prevent $\mathrm{CO}_{2}$, the card offers a portfolio of carbon credits to offset unavoidable emissions permits, making the day-to-day more "user-friendly" environment. In choosing this card, customers have access to special discounts on the purchase of goods and services more energy efficient, including a cash-back program that offers them carbon credits to offset emissions. The card gives therefore $\mathrm{CO}_{2}$ credits, which means that the amount accumulated in the cash-back program is channelled to projects that absorb or prevent carbon dioxide. Emissions from the production and distribution of the card are quantified and compensated. To that extent, it can be said that the name Card Zero Carbon is justified, and it is a card with no effect on climate.

Tapada Nacional de Mafra is the first project to benefit from funds provided by the Card Box Carbon Zero. This is an area of 50 hectares, which is strongly affected by the fires of 2003. Integrating project in forest area, the Card came enable the proper management of this area, with special attention to newly installed stands and processes of natural regeneration. It is intended to ensure sustainable forestry, fire 
protection and enhancement of biodiversity. The project ensured the monitoring of the action over 30 years. The project includes the development and implementation of a management plan that will allow carbon sequestration of a total of about 3,000 tons $\mathrm{CO}_{2}$ equivalent $\left(\mathrm{CO}_{2} \mathrm{e}\right)$.

The recent innovation in this area is called "cash carbon calculator". Installed at the site of the institution allows the user to calculate their carbon footprint quantifying the emissions associated with daily life from issues that relate to two key areas: housing (domestic consumption) and mobility (use of means of transport).

Support scientific research. Along with these actions that directly target the environmental, Caixa is integrating its activities in the promotion of scientific research as central to the evolution of knowledge and change attitudes and mentalities.

The role of education is central to sustainable development. Hence: firstly, and according to the desideratum of increasing the financial literacy of potential users, CGD has created mechanisms that are simple, practical and accessible, to encourage savings. This has created a financial education program, called Positive Balance, with access to the Net (www.saldopositivo.cgd.pt) to customers and non-customers. The contents are useful application in the daily management of the family budget, and include suggestions for energy saving approach of diagnostic tools to prevent financial indebtedness, financial products etc..

For young people there is a program - Ciclo da poupança (cycle of savings) which points to the need for savings and simple formulas to achieve them. It led in 2007 to a game with hundreds of agencies and students of 1st and 2nd cycles, on the celebrations of world savings.

Most interesting, the Programa Nova Geração de Cientistas Polares (New Generation of Polar Scientists Programme) results of a collaboration with the Portuguese for the international polar year. It assigns scholarships to young scientists for studies to focus on relevant issues of climate change and its effects (biology, physics of the atmosphere, etc.) on Antarctica region. Simultaneously, Portuguese started a major campaign in Antarctica with the participation of Portuguese scientists held until 2009, November. The Committee for the polar year, consisting of researchers from several universities in Portugal and its action promotes the integration of young scientists in the work of teams who are developing this area of science, creating critical mass and promoting the image of the Portuguese Science World.

The lectures Um Alerta Global para o Desenvolvimento Sustentável (A Global Warning for Sustainable Development): In this field, there are alerts for sustainable development by supporting a series of conferences in Culturgest promoting discussion of relevant issues and with the participation of some of the most significant researchers (with themes such as climate change, human rights, sustainable development and the information society, architecture responsible).

A way that promotes the development of skills in the area still refers to the Concurso de Design de Mobiliário com Materiais Reciclados (Furniture Design Competition with Recycled Materials) that challenged the young people of Portuguese universities and polytechnics to display their talents, contributing to the development of proposals for eco-design and thereby furthering rows of recycling.

And others:

- Publications (the magazine Azul);

- Renewable energy credit programs, with special conditions for acquisition and installation of equipment;

- My energy program, in partnership with EDP-integrated solution of micro-generation solar thermal, 
photovoltaic and wind power for small and medium consumers.

Obviously that environmental sustainability should not be disconnected from the other two pillars of development: economic and social. We do not want to enlarge this communication, but we would like to stress the importance of CGD's solidarity actions, as well as actions to support culture and sport of its employees and the community, or their efforts on the transparency of information.

\section{Vale and Environmental Sustainability}

\section{Environmental Issues in Brazil}

The evolution of society especially after the re-democratization of Brazil and the 1988 Constitution, which guaranteed political participation through questioning of autonomous social organizations, NGOs and other institutions, and international pressure of all kinds on the expansion of economic projects in the region showed a new way to analyze the environmental and social impact.

With the new ecological and social, the state itself has changed its approach to geopolitics to the area and began to seek a return to society of the projects to be implemented and also their approach to sustainability, long-term perspective, the degree of exploration and employability. To demonstrate this, the companies that own or want to develop projects in the region began to show a series of socio-environmental in their statements, in addition to campaigning for clarification of its participation in the region. The main tool for informing the government and investors on these issues is the balance social and environmental accounting that can come as part of the accompanying financial statements have already been published by the company.

\section{The Company}

Vale (originally state-owned enterprise, privatized in 1997) called Companhia Vale do Rio Doce was founded by decree on June 1, 1942, with operations concentrated in Minas Gerais, with the purpose of mining iron, during the government of President Getúlio Vargas, then a dictatorship began with the revolution of 1930 .

The connotation of the nationalist government Vargas was incorporated in the vision of the company that originally served only the domestic demand particularly CSN (Companhia Siderurgica Nacional). However, in the 60s the company takes an entrepreneurial leap and is now exporting iron ore to Japan. This change of attitude will take the company to the next level to have a place to insert performance as an exporter of long range.

The evolution of the Vale over the years caused the company to turn into a mining giant, the second mining company in the world at the beginning of the century, when the company had undergone a radical transformation in its concepts with its privatization in 1997. Vale expanded throughout the country, with investments in various areas of economy, such as pulp manufacturing, logistics, rail and port, aluminum fabrication, reforestation energy than the holding of all kinds of minerals such as gold, manganese, bauxite and kaolin.

In these circumstances, the company began operating in 14 of the 27 states, with much emphasis on the Eastern Amazon in the states of Para and Maranhão, from the Carajás project installed in 1980 in Pará, the largest mining project in the planet and having the iron ore with the best quality. The impact of this project, as well as other smaller but no less important and constant social and environmental concerns, the company 
became the main economic actor in the region. Since its privatization, the dialogue between the society and the company has been focused on the economic developments and sustainability, which are possible to be reached or just discussed in this process.

The company Vale is the second largest diversified mining company in the world market value. World leader in the production and export of iron ore and pellets, and an important producer of nickel, copper concentrate, bauxite, alumina, potash, kaolin, manganese, ferroalloys and coal, the company has offices and operations in over 30 countries on five continents. Vale was the first Brazilian company to achieve the rating of investment grade and the first Brazilian company to trade its shares on Euronext (Paris).

The company has gained momentum with the ore extraction in the Amazon, more specifically in the Carajas region, located in the southeastern state of Para Company, in its first year, produced 40 thousand tons of iron ore, equivalent amount that is loaded per hour today.

Vale has diverse activities within the mining sector. The company operates in the segments below:

- Ferrous: Iron ore and pellets, manganese and ferroalloys;

- Non-ferrous: Kaolin, potash, copper and nickel;

- Logistics: Railroads, port terminals, coastal shipping and logistics solutions;

- Aluminum: Bauxite, alumina and aluminum;

- Energy: Eight hydroelectric dams, seven of which are already in operation;

- Coal.

Figure 1 shows the diversity of work, identifying what each product represents the composition of gross revenue.

\begin{aligned} Iron ore & \multicolumn{1}{c}{$15.50 \%$} \\ \cline { 2 - 2 } Nickel & \multicolumn{1}{c}{$11.02 \%$} \\ Pellets & \multicolumn{1}{c}{$7.90 \%$} \\ \cline { 2 - 2 } Copper & $5.27 \% \\$ Logistics & $4.17 \% \\$ Aluminum products & $3.48 \% \\$ Others & $1.67 \% \\$ Coal & $1.50 \% \\$ Manganese and ferro-alloys & $1.04 \% \\$ PGMs: Platinum group metals & $0.77 \% \\$ Potassium & $0.5 \% \\$ Kobalt & $0.55 \% \\$ Precious metals & $0.54 \% \\$ Operational services of pelletizing plants & $0.29 \% \\$\cline { 2 - 2 } & $0.15 \%\end{aligned}$

Figure 1. Composition of gross revenue. Source: Vale.

CVRD holds maximum production of nickel, bauxite, alumina, copper, thermal coal, cobalt, platinum group metals and precious metals. The company guarantees sales maxima of iron ore, nickel, copper, alumina, cobalt, precious metals, platinum group metals and thermal coal.

Privatized in May 6, 1997, the company had a net worth in 1997 of U.S. \$350 million, with a market value 
around $\$ 10.5$ billion by offering 11 thousand direct jobs. In less than a decade after massive investment, the company increased nearly 10 times its gross revenue, according to data presented in Figure 2.

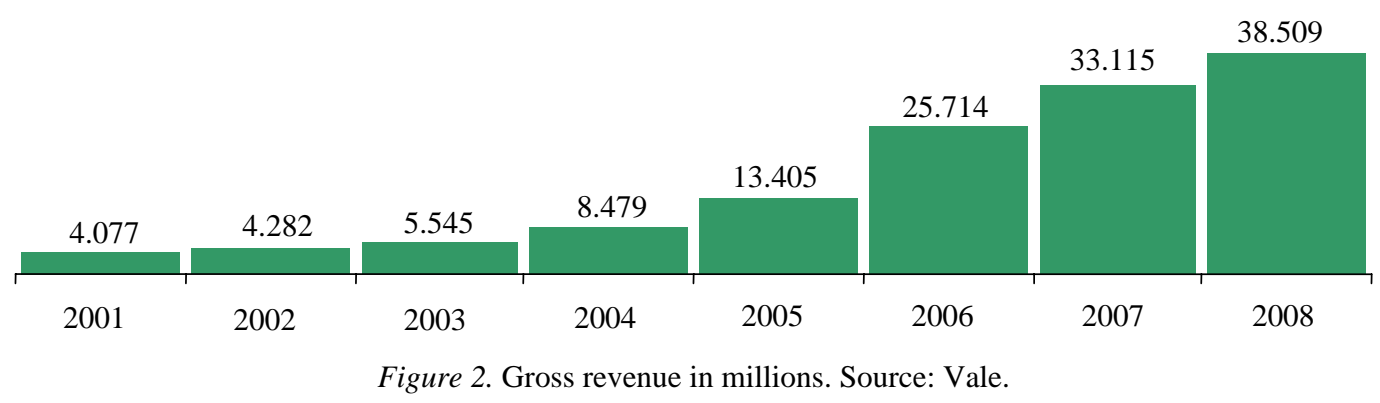

The privatization of Vale, whose sale is questioned today, brought the company a sum demeaning investment. On August 11, 2006, CVRD made a public offer of \$18 billion for Inco, Canada, owns the largest reserves of nickel in the world, becoming a historic deal to offer: more than buying a Brazilian company has made abroad, making Vale one of the largest nickel producers in the world, with production of 234,900 tons in 2006.

The transaction increased the market value of Vale and in December 2007 the company was worth U.S. \$151,711 billion, a number of employees from 152,724 in 2007.

In 2008, the company was considered the most mine that invests in its production process, as shown in Figure 3.

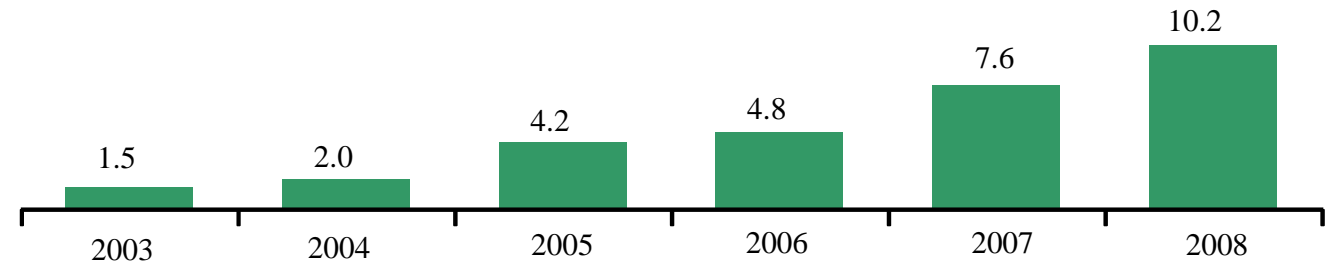

Figure 3. Increased investment in mining company in the world (billions). Source: Vale.

According to the data, the company was worth more investment and increased profitability after its privatization in 1997. The process of privatization of CVRD requires a brief statement.

\section{Vale and the Environment}

According to the company report, the essence of its work is the search for balance between socio-economic development of territories and maintaining the quality of natural resources, biodiversity and life.

For that, Vale made continuous investments in the management of environmental impacts of operations and research of new technologies that improve the environmental control systems. The guidelines that guide the actions are explained in the policy of sustainable development of Vale, a document that guides the process from decision making to the actions performed on the day to day operations.

Vale considers the respect for the environment a key component of its sustainability strategy, seeking to balance environmental protection and economic development. To this end, the company has an environmental policy, in which commitments to environmental aspects are clearly explained.

The company's main points of its environmental policy:

- Maintain an environmental management system, aiming to ensure that activities comply with applicable 
laws and standards set by the company, in the absence of specific legislation, Vale will implement the best measures of environmental protection and minimizing risk;

- Educate and train employees to act in an environmentally responsible, ensuring the implementation of environmental policy;

- Develop research and incorporate new technology for continuous improvement activities, aimed at reducing environmental impacts and consumption of energy and matter;

- Maintain ongoing dialogue with its employees and the community, aiming at improving environmental actions;

- Strive to their subsidiaries and affiliated companies to adopt practices consistent with this environmental policy;

- Request their products and services suppliers with proven environmental quality.

Policies, standards and procedures are defined by the Department of Environment and Sustainable Development, which coordinates the Management System for Environmental Quality (SGQA) of the company, setting guidelines and targets, monitoring the development of environmental performance and providing tools for managing the environmental aspects related to the activities, products and services of Vale.

The company is also in a process of discussion and alignment of Environmental Policy with the subsidiaries. In the context of the Management System of Environmental Quality there are developed measures for monitoring, conservation, environmental protection and recovery to ensure the maintenance and recovery of ecosystems in which Vale operates.

The environmental management system is based on the guidelines ISO 14001 (International Organization for Standardization). Periodically, the transactions are subject to external audits.

In recent years, important achievements were obtained in the rational use of water and energy, waste disposal and the awareness of people to environmental quality. Vale is aware that there are opportunities for improvement and committed to continuous improvement in building an environmentally friendly business model.

According to the report of the company, Vale has a great concern for environmental issues, and as a consequence of this there are the significant investments in their environment. The commitment is not limited to environmental control systems required. The environmental aspect is an important component of the evaluation of new projects and decision-making investment for expansion. Expenditures are monitored monthly and reported quarterly to the general public, and we count on periodic financial audits.

The relationship with the various stakeholders is present in environmental management. In each area where Vale acts, seek to be agents of change, listening demands, proposing alternatives and integrating other social actors in the effort to find solutions to environmental issues.

The volume of resources invested in the environmental area for Vale in 2008 was U.S. \$678 million, almost 50\% higher than that achieved in 2007. Most of the resources allocated to three lines of expenditure:

- Acquisition and implementation of environmental control equipment, aiming to improve performance in existing operations;

- Maintain environmental and geotechnical safety of dams and waste dumps;

- Reforestation and rehabilitation of degraded areas, which form the program Vale "Florestar". 


\section{Environmental Quality}

The management system of environmental quality determines the development of effective monitoring, conservation, environmental protection and rehabilitation, aimed at ensuring the maintenance and recovery of ecosystems in which Vale operates. The system is based on the guidelines of ISO 14001 (International Organization for Standardization) to which were added additional aspects that make up the standard of environmental quality in Vale. Aiming to assess the management and guarantee the evolution of performance, multiple transactions are submitted periodically to internal and external audits.

Policies, standards and environmental procedures of a general nature are defined corporately, and management is under responsibility of operations and business areas.

\section{Social Aspects}

The quest to build a legacy of social, economic and environmental positive in regions where Vale operates is one of the principles that underlie the Sustainable Development Policy in Vale.

Activities, especially mining, are limited to the lifetime of the mineral deposit and therefore the presence in a particular place, in general, is finite.

The challenge is to make Vale, along the mineral cycle, actions catalyst of regional economic vocations, which can ensure the perpetuity of social welfare in equilibrium with the environment. In that quest, Vale performs management actions that enhance the positive effects of the presence of Vale, reduce the social risks of operations and at the same time, contribute to strengthening the foundations for local development in the long run. Vale invests in integration with public officials and social workers to encourage:

- The hiring of local employees and suppliers;

- Education for human development, for work and income generation;

- Planning the use of taxes generated by the operations of the company;

- The diversification of local economies;

- The strengthening of institutions;

- Environmental conservation and cultural heritage.

Thus, the company seeks to build social networks transparent, based on dialogue and permanent respect for the culture of each people. At the same time, Vale invests in management tools to foster the development of the territories. Its intention is to build the foundations for continuous improvement of quality of life.

\section{Management of Local Development}

Vale has several programs and tools, in different areas and regions of operation, to manage social and environmental impacts arising from the activities.

The analysis of the feasibility of implementing projects, adopts the methodology Front-End Loading (FEL), which covers social, health, safety and environment, and economic and operational risks.

Furthermore, based on environmental assessment, social and economic performed in the EIA (Environmental Impact Assessment and Impact Report for the Environment), are considered potential impacts of the presence of Vale regions in the phase of licensing and deployment projects.

These tools, together with the diagnoses made by Socioeconomic Vale Foundation, guided Programs Management Environmental and Socioeconomic Impacts, intended to find mechanisms to avoid or minimize 
negative impacts and maximize positive impacts on the performance of Vale. These programs are implemented according to the needs of each project and consider the particularities of each region. Through these tools, it identifies the main impacts associated with the presence of mining. Among them stands out:

- Direct economic impacts positive: Generation employment, vocational training, increased tax collection, hiring of local products and services, investments in infrastructure;

- Direct negative economic impacts: Environmental impacts such as dust and noise, interference with land use, risks of accidents.

Positive indirect economic impacts, increase the wage, benefit income generation, leverage of other economic sectors, suppliers of attraction, development of local suppliers, attraction of investments from various spheres of public and private sectors. Indirect negative economic impacts: pressure on infrastructure and public services, due to population increases, speculation in remote areas, due to the low housing supply and high demand, generation of economic leakage effects, due to the hiring of suppliers and employees of other regions, lack of businesses and experts on site.

\section{Programmes and Management Impact Practices}

In order to leverage and maximize the positive outcomes of Vale in the territories, working with structured programs in the various relationships that Vale set.

Qualification. Seeks to maximize the hiring of residents of the localities where it operates, especially in developing countries and remote areas.

Vale invests in professional training programs related to mining activities and other activities of the local economy. Through these programs, we seek to contribute to employment and income generation and diversification of the economy of the communities where it operates.

Relationship with communities. At all stages of the company's ventures-inception to the closing of the transactions - account with a team of Institutional Relations and Communication. Programs for community relations are based on a dialogue between the permanent and participatory community and Vale. Programs include visits to mining communities, meeting with leaders and participatory forums. In addition, we seek to establish a direct dialogue and transparent with not only the community but also with the local government in order to build a harmonious relationship.

Relations with traditional communities. Give special attention to these traditional communities in the localities where it operates. The basic guideline of the Program Interaction with Indigenous Communities is to ensure that the benefits generated by the project are enjoyed by the indigenous communities, respecting their cultural traditions so as to avoid, minimize or offset any adverse effects that the activity can.

Culture appreciation. It is understood that one can contribute and participate in programs of recovery, revitalization and protection of cultural property. Support to projects and settle agreements restoration of cultural heritage and archaeological sites where it operates. An example is the project of rescuing the language of the Kanak people.

Besides these programs, implanted directly in the units, Vale foundation works for the development of communities where Vale is present, helping to empower people and respecting local cultural identities through social programs structured. 


\section{Investment in Infrastructure}

Over the past three years, the amount applied was approximately \$169 million. The fall in investment in infrastructure in 2008 is due to the completion of projects.

In coming years, southeastern Pará need significant investment to remedy deficiencies in existing social infrastructure and prepare the country for projected economic growth of $18 \%$ per annum. To deal with these investments, the municipalities could count on an ability to own investment which will generate a gross savings of \$504 million between 2006 and 2010.

This is one of the main conclusions of the Integrated Diagnostic Socioeconomics of southeastern Pará, a study between 2006 and 2007, Vale and Vale foundation, under the auspices of Diagonal Urbana, a Brazilian consultancy specialized in integrated social management that counts with the participation of communities.

Although a significant structural deficit, the Southeast of Pará presents itself as a world of opportunities for sustainable development. After all, it is one of the regions of the world's richest in natural resources and major mineral provinces of the world. Since it began operations in the region, in the 80s, Vale has been supporting the development of the municipalities that are in their area of influence, while helping to preserve an area of $8,000 \mathrm{~km}^{2}$ of native forest in Mosaico of Carajas.

Investments in infrastructure, urban sanitation, education and culture have contributed significantly to the development of the region. Even the company's growth over this period brought more opportunities for skills and employment for residents, more business for local suppliers and increase tax collection by government agencies, contributing to the local socioeconomic development.

Vale currently has 15 projects in the area and wants to make new investments, even to the total value of U.S. $\$ 13$ billion (2003, 2010). To increase its presence and have an even more effective and socially responsible, Vale and his foundation have decided that, first, it was necessary to know the region, understanding the present moment and projecting the future.

Diagnostics marks only the beginning of the Integrated Management Plan Socioeconomics Southeast of Pará, which also includes the steps of preparing and implementing the Plan of Action Planning, which is already being prepared in 2007, determines what should be done investments and how each party should participate. Already taking action is the stage of implementation of improvements, including efforts to seek financing. "This is a powerful tool that allows Vale contribute to sustainable development in regions where it operates”, says Silvio Vaz, director of the Vale Foundation. Plan includes six municipalities (Parauapebas, Canaan dos Carajás, Curionópolis, Maraba, Ourilândia North and Tucumán), and influences Eldorado dos Carajas.

\section{Health and Safety Activities and Policies}

In 2007, it has been continuing to carry out the strategy for health and safety through various activities, among which are:

- Policy review health and safety—The new text of the policy specifies the commitments and the basics of managing Health and Safety, which embody the value of respect for life;

- Elaboration of requirements for systemic health and safety-The standard defines what must be done to ensure the proper development of the organizational processes of Vale. These requirements stem from the health and safety policy and its principles. They are the ones that underlie the procedures, tools and 
performance indicators of health and safety management;

- Elaboration of requirements for critical activities (RACs) - The requirements established for the execution of critical operational activities, with the purpose of preserving people's lives, ensuring the integrity and protecting health in all areas of the company, so as in its subsidiaries and affiliates. The 10 activities of greater risk appetite for Vale are working at height, motor vehicles, mobile equipment, blocking and signalling, cargo handling, confined space, machine protection, slope stabilization, and detonated explosives and chemicals;

- Implementation of information system health and safety—In order to improve the management and flow of information from Health and Safety, it begins the deployment of a single information system for Vale in Brazil. The tool will support management decisions, according to the results of business areas;

- Membership in the global business coalition on HIV/AIDS, Tuberculosis and Malaria-GBC (Global Business Coalition against HIV/AIDS, Tuberculosis and Malaria) - Joins the group of more than 200 member companies of the GBC, an organization aimed at mobilizing resources for initiatives for combating and prevention of HIV/AIDS, tuberculosis and malaria;

- Event “Construction”- In June and July 2007, approximately 2.5 thousand leaders in Vale gathered in 19 cities of Brazil, to build together the foundations of a culture of prevention in health and safety.

The new health and security policy of Vale, released in March 2008, establishes the following commitments:

- To control all risks associated with activities, processes, facilities, products and services;

- To act proactively in managing risks to health and safety of persons and facilities;

- Meet the legal requirements of health and safety and to take voluntarily;

- To continuously improve their performance in health and safety through the improvement of activities, processes, products and services, focusing on the use of innovative solutions and developing people;

- To encourage the development of performance in health and safety service providers;

- To maintain communication channels with the communities where operate and other stakeholders, so as to remain always alert to the influence of its operations in the health and well-being of people.

Since 2006, the performance goal of workplace safety (accidents with remote and internal corporate standards) is tied to variable pay of employees. In 2007, the process changed so that in contemplating the health data. The set of actions has already implemented and the beginning of the process of cultural transformation has already shown some results.

Between 2005 and 2007, various measures to improve management of health and safety are implemented, for example, setting targets covering issues of health and safety for all departments and the intensification of awareness campaigns.

Starting from 2007, there began a process of improvement of registration procedures and data collection on health and safety. Implanted with the classification standards of accidents according to the rules Occupational Safety and Health Administration (OSHA), the Agency for Safety and Health at Work in the United States, and held several training initiatives and awareness for employees in order standardize recording information.

With the implementation of this process, in 2007 it moved to separate the care of first aid records of accidents without removal of permanent employees. In coming years, we should replicate this model for employees to third parties. 
Regarding the rate of accidents with lost time, the objective is worth a significant reduction of $33 \%$ over the period 2005 to 2007. This means that the accidents of greater severity were reduced. The perspective is that in the coming years, accident rates have continued with clearance reduction, both because of the improvements implemented as stability in the form of gathering and recording data. In this sense, began also to participate in a working group of ICMM (SCHE Benchmarking) in order to align indicators of health and safety and occupational hygiene.

With regard to risk prevention and health guarantee, Vale maintains a rigorous system for identifying health risks in all its units. The goal is to use this information to the creation of specific programs that can be deployed in a corporate, promoting an attitude of prevention by employees, relatives and the communities in which CVRD operates. By the end of 2007, risks were identified by the following diseases:

- Occupational: Musculoskeletal diseases, back pain, risk of hearing loss and pneumoconiosis;

- Endemic: Intestinal parasites and diseases carried by animals, dengue, malaria, Chagas disease, yellow fever, hepatitis A and B, HIV/AIDS, leishmaniasis, and worms. Among the programs maintained by the company are: Campaign to prevent sexually transmitted diseases_-STD/AIDS, World Day to Combat AIDS, workshops on alcohol and smoking, and prevention campaigns against cancer and diabetes; support group for diabetics, hypertensives and people with cardiovascular risks; program of gym work, education program affective-sexual (Vale youth-developed by Vale foundation), aimed at young people from nearby communities in order to guide the sexual life and prevent the occurrence of sexually transmitted diseases; campaigns of vaccination against influenza, and inspections to prevent and treat dengue and yellow fever. Besides these initiatives, Vale offers health plans to their employees and third parties as described in the job session and people development.

Such efforts have earned public recognition. The Healthy Living Program, Albras, won in 2005, the social value award (jury of experts and jury) in the category "quality of working environment”, and in 2007, Lennart Levi Award in the category "poster enterprises", VII Congress of Stress of ISMA (International Stress Management Association). Vale invested U.S. \$25.2 million by mid-2009.

According to the testimony of some local politicians, royalties would be a form of compensation to alleviate the problems acquired with the implementation of projects in Vale Hall of EPC. They would also help solve problems such as sanitation, health, etc.. Socially critical areas now considered by municipalities, whose solutions would not be viable only with the transfers of state resources and the union.

\section{Concluding Remarks}

\section{CGD}

It is too early to gauge the results of this strategy. The impact of the conduct of social responsibility, especially in this aspect of environmental sustainability can only be realized in a longer period. In any case, and a perspective that brings us closer to an ex-ante, it is possible to draw attention to the following notes conclusive:

Firstly, it should be noted that have been recorded signals of recognition by the community's action on CGD activities. Besides the prize in the study cited "trust marks" where CGD was considered Trusted Brand in Portugal and highlighted its role in the environmental sphere, the program "Planet Thanks" was awarded the prize "effectiveness in social responsibility". Another public recognition comes from studies of brand score 
which show the association of CGD brand social responsibility and a strong brand association culture.

How far this activity has had an impact on the market and the performance of CGD is a matter for future research.

Second, is to recognize the importance of tradition in terms of social responsibility. Companies where management strategy always believed in ethical and solidarity with their colleagues and with the community to share these processes as an important "capital".

Thirdly, social responsibility is certainly not just philanthropy, but can/should also include this activity. Increasingly, social responsibility, in general, and promoting environmental sustainability, in particular, carries out an operation more effective if integrated into the global perspective of business and relationship with their surroundings.

Finally, the CGD case highlights the advantages of establishing a coherent and integrated strategy, with a thread that organizes the various lines of action and their actions. In this case, the establishment of the whole strategy around climate change avoids dispersion and stray image of a policy or meaningless without clear objectives. It reinforces the brand image with a seal of pertinence and internal coherence that enables more effective performance.

\section{Vale}

The company Vale, privatized in 1997, formerly CVRD, is one of the biggest agents of social change in the state of Para in Brazil, more precisely in the region it operates. The consequences of the trade of mineral resources in regional terms, although they involve the production of very different goods, are highly valued by companies that have been installed at different points historically which retain important and decisive singularities with respect to the impact on regional development processes.

Vale is a company that owns its own Sustainability Report, with great emphasis on its search for balances between economic development and preservation of natural resources. It tries to act with strict control of aggression to the environment, and involvement with social problems of the localities in which acts, often performing the role of provider of social investments like education, health, sanitation, urban development, appreciation of culture and professional training.

The report follows the company's main document, sharing the costs and investments in sustainability. Being a mining company and generating its wealth from non-renewable resources, the pressure on Vale is expected to grow further in the future because acting on a global scale, its main and largest projects are located in the Eastern Amazon state of Pará with large concerns about resources.

\section{Final Note}

After some individual considerations, it is necessary to refer some important ideas about global concerning.

First, it is necessary to join some ideas about what is relevant in these two cases that give a particular idea about both companies in both countries, convergent and divergently. So, it is first necessary to say that both companies are concerned about the way to show society the idea they have and about the way they are related to society.

Second, it seems important to highlight that corporate social responsibility must not be confounded with philanthropy. The responsible positioning of both companies must have some results in terms of the 
performances of companies. And consequently, there is yet lot of research needed in terms of constructing economic indicators to reveal the impacts of the corporate social responsibility actions on the profits and other economic results of firms' activity.

Third, this study also reveals the importance of developing a research on the themes of business ethics in companies and the respective impact on organizational structure in companies and their relationship with stakeholders, both internal and external to the company.

Finally, this study is mostly an empirical based research. However, it also reveals that there are also theoretical issues related to corporate social responsibility that must be considered in the agenda of the researchers and scientists interested on these fields of investigation. The traditional economics of natural resources and environment has a focus, in terms of regulation in the presence of governmental and public policy. Maybe some economical developments can be developed using the idea that private organizations can supply some rules and regulation, supplying additional social assistance and creating conditions for the efficient use of natural resources.

\section{References}

Becker, B. K. (1994). Repensando a questão ambiental no Brasil a partir da Geografia Política. In M. C. Leal et al. (org.), Saúde, ambiente e desenvolvimento, I. São Paulo: Hucitec.

Becker, B., et al. (1995). Geografia e meio ambiente no Brasil (2nd ed.). São Paulo: Hucitec.

Bergamini, J. S. (1999, June). Contabilidade e riscos ambientais. Revista do BNDES, Rio de Janeiro, 6(11).

Bezerra, M. C. L., \& Bursztyn, M. (cood.). (2000). Ciência e tecnologia para o desenvolvimento sustentável. Brasília: Ministério do Meio Ambiente e dos Recursos Naturais Renováveis: Consórcio CDS/UNB/Abipti.

Brundtland Report. (1987). Our common future. Oxford: Oxford University Press

Brüseke, F. J. (2003). O problema do desenvolvimento sustentável. In Cavalcanti, Clóvis (org.), Desenvolvimento e natureza: estudos para uma sociedade sustentável (4th ed.). São Paulo: Cortez; Recife: Fundação Joaquim Nabuco.

Camargo, A., Capobianco, J. P. R., \& Oliveira, J. A. P. (org.). (2004). Meio ambiente Brasil: Avanços e obstáculos pós-Rio-92 (2nd ed.). São Paulo: Estação Liberdade: Instituto Sociombiental; Rio de Janeiro: Fundação Getúlio Vargas.

CGD. (2009). 133 Anos a construir O Futuro: Um Modelo sustentável. Entrevista Fernando faria de Oliveira-O Futuro Sempre Presente. Azul, 39, 22-37.

Coelho, M., Filipe, J. A., \& Ferreira, M. A. (2011). Environmental sustainability as a dimension of corporate social responsibility: The case of CGD—Caixa Geral Depósitos/Portugal. International Journal of Academic Research, 3(1).

European Commission. (2001). Green paper-Promoting a European framework for corporate social responsibility. Retrieved 18 September, 2010, from http://eur-lex.europa.eu/LexUriServ/site/en/com/2001/ com2001_0366en01.pdf

Ferreira, A. C. S. (2003). Contabilidade ambiental. São Paulo: Atlas.

Filipe, J. A. (2009). A note on the drama of the commons. How to deal with an old problem in natural resources: The resources overexploitation. In International Journal of Academic Research. Ijar: Azerbaijan.

Filipe, J. A., Coelho, M. F., Ferreira, M. A. M. (2007). O drama dos recursos comuns. Sílabo: Lisboa.

Furtado, C. (1992). Brasil, a construção interrompida. São Paulo: Paz e Terra.

Kroetz, C. E. S. (1999). Auditoria do balanço social. Revista Brasileira de Contabilidade, 116, mar/abr.

Kroetz, C. E. S. (2000). Balanço social. São Paulo: Atlas.

Melo, N. F., \& Froes, C. (2001). Gestão da responsabilidade social corporativa: O Caso brasileiro. Qualitymark, Rio de Janeiro.

Paiva, P. R. (2003). Contabilidade ambiental. São Paulo: Atlas.

Sachs, I. (2000). Caminhos para o desenvolvimento sustentável. Rio de Janeiro: Garamond.

Santos, R. (1980). História econômica da Amazônia (1800-1920). São Paulo: T.A. Queiroz.

Tinoco, J. E. P. (2004). Balanço social. São Paulo: Atlas.

Tinoco, J. E. P., \& Kraemer, M. E. P. (2004). Contabilidade e gestão ambiental. São Paulo: Atlas.

Vale, S. A. (2007). Relatório de sustentabilidade.

Vale, S. A. (2008). Relatório de sustentabilidade. 